This item was submitted to Loughborough's Research Repository by the author.

Items in Figshare are protected by copyright, with all rights reserved, unless otherwise indicated.

\title{
Assessing stiffness of nanofibres in bacterial cellulose hydrogels: Numerical- experimental framework
}

PLEASE CITE THE PUBLISHED VERSION

http://dx.doi.org/10.1016/j.msec.2017.03.231

\section{PUBLISHER}

(C) Elsevier

VERSION

AM (Accepted Manuscript)

\section{PUBLISHER STATEMENT}

This work is made available according to the conditions of the Creative Commons Attribution-NonCommercialNoDerivatives 4.0 International (CC BY-NC-ND 4.0) licence. Full details of this licence are available at: https://creativecommons.org/licenses/by-nc-nd/4.0/

\section{LICENCE}

CC BY-NC-ND 4.0

\section{REPOSITORY RECORD}

Gao, Xing, Emrah Sozumert, Zhijun Shi, Guang Yang, and Vadim V. Silberschmidt. 2019. "Assessing Stiffness of Nanofibres in Bacterial Cellulose Hydrogels: Numerical-experimental Framework". figshare. https://hdl.handle.net/2134/25611. 


\title{
Assessing stiffness of nanofibres in bacterial cellulose hydrogels: Numerical-experimental framework
}

\author{
Xing Gao ${ }^{\text {a }}$, Emrah Sozumert ${ }^{\text {a }}$, Zhijun Shi ${ }^{\mathrm{b}, *}$, Guang Yang ${ }^{\mathrm{b}}$, Vadim V. Silberschmidt ${ }^{\mathrm{a}, *}$ \\ ${ }^{a}$ Wolfson School of Mechanical, Electrical and Manufacturing Engineering, Loughborough University, Loughborough, UK \\ ${ }^{\mathrm{b}}$ College of Life Science and Technology, Huazhong University of Science and Technology, Wuhan, China
}

A B S T R A C T

\begin{abstract}
This work presents a numerical-experimental framework for assessment of stiffness of nanofibres in a fibrous hy-drogel - bacterial cellulose (BC) hydrogel - based on a combination of in-aqua mechanical testing, microstructur-al analysis and finite-element (FE) modelling. Fibrous hydrogels attracted growing interest as potential replacements to some tissues. To assess their applicability, a comprehensive understanding of their mechanical response under relevant conditions is desirable; a lack of such knowledge is mainly due to changes at microscale caused by deformation that are hard to evaluate in-situ because of the dimensions of nanofibres and aqueous en-vironment. So, discontinuous FE simulations could provide a feasible solution; thus, properties of nanofibres could be characterised with a good accuracy. An alternative - direct tests with commercial testing systems - is cumbersome at best. Hence, in this work, a numerical-experimental framework with advantages of convenience and relative easiness in implementation is suggested to determine the stiffness of BC nanofibres. The obtained magnitudes of 53.7-64.9 GPa were assessed by calibrating modelling results with the original experimental data.
\end{abstract}

Keywords:

Stiffness

Hydrogel

Nanofibre

Bacterial cellulose

\section{Introduction}

Some fibrous hydrogels demonstrate a good potential for use in various bioengineering applications, such as replacement of human tissues $[1,2,3,4,5]$ and scaffolds for tissue regeneration in vitro $[6,7,8]$ mainly thanks to their (i) good biocompatibility $[9,10]$, (ii) mimic architecture [11] and (iii) mechanical properties similar to real tissues [12]. Recently, a growing interest to qualify their applicability is to investigate their mechanical behaviour under application-relevant conditions $[13,14]$. Still, a lack of knowledge in a real-time response to deformation is due to poor detectability of microstructural changes in a nanofibrous network. That complicates predictions of their mechanical behaviour and service life for candidate materials implemented into body environment defined by interaction with native tissues. Many fibrous hydrogels, like bacterial cellulose (BC) hydrogel (see Fig. 2a-c), consist of a solid phase - a fibrous network - embedded into a liquid phase. Normally, such a network acts as a main component in a load-bearing process. By controlling such parameters of network as the volume fraction and orientation distribution of fibres, the overall mechanical behaviour of the hydrogel could be optimized for a certain application $[15,16]$.

Various techniques were used for mechanical characterisation of fibres, such as tensile and bending tests, indentation, etc. [17].

\footnotetext{
* Corresponding authors.

E-mail addresses: shizhijun@hust.edu.cn (Z.Shi), V.Silberschmidt@lboro.ac.uk (V.V. Silberschmidt)
}

Considering a diameter of nanofibres, atomic-force-microscopy (AFM) based tests, such as nano-tension [18], nano-bending [19,20], nanoindentation [21], together with custom-made nano-testing systems [22, 23] were employed instead of commercial mechanical-testing systems. For BC nanofibres, in an early study, Guhados et al. [24] measured their axial modulus by performing nanoscale-three-point-bending tests using an AFM cantilever; the obtained magnitude was $78 \pm 17 \mathrm{GPa}$. Their results confirmed a trivial effect of fibre diameter on its axial modulus. But the modulus of an isolated single fibre might be different from that for the natural state. Such nano-testing allows directly measurements of the axial modulus, but the technique is expensive, time-consuming and difficult to implement; besides, repeatability of results is poor. Analysing micro-deformation of fibres under external tension, a Raman-spectroscopy-based technique was also used to estimate the axial modulus of BC nanofibres, and the obtained values of $114 \mathrm{GPa}$ and 79-88 GPa were documented by Hsieh et al. [25] and Tanpichai et al. [26], respectively. The technique employed an assumption that a Raman band shift is proportional to the applied stress; thus, the results depend on closeness of the used empirical relations to real-life behaviour.

Different theoretical approaches were employed to assess mechanical properties of cellulose-based composites. Considering a BC hydrogel as a general dual-phase composite, its overall properties can be described in terms of properties and volume fraction of each component, as well as their interactions. Retegi et al. [27] evaluated structure-function relationships of a BC; Krenchel-Cox network theories were used to 
calculate an axial modulus of 28.2-31 GPa. Homogenization schemes can connect effective properties with contributions of each component accounting also for microstructure (i.e. a character of distribution of constituents). In many schemes, the inclusions are considered surrounded by an infinite matrix. In a recent work, Josefsson et al. [28] used properties of nanofibres and a matrix to predict an effective elastic modulus of nanofibrillated cellulose based on a Mori-Tanaka homogenization scheme. Thus, an inverse process based on homogenization approximation could be a potential way to assess properties of constituents based on effective ones; still, considering the complexity of interaction terms in stiffness contribution tensor, it may be currently infeasible.

Inverse parameter estimation of properties of fibres in networks using FE method is also possible [29]. A core technique is to validate an approximate value with a global response obtained with testing and network behaviour assessed with numerical modelling. Theoretically, if a model could reflect geometries and material properties of a real material, the results could be considered reliable. Thus, many efforts were made to develop more realistic models in order to reproduce complex geometries of fibrous materials in FE models. A fibre-deposition method is taken into consideration in some studies, with fibres aligned based on a fibre orientation distribution function obtained from SEM or X-ray images through digital-image processing $[30,31,32,33]$. Such models can imitate movement and rotation of fibres and bond points enhancing stiffness of a single layer fibrous network [30]. Continuous FE models were proposed to simulate deformation behaviour of a variety of fibrous materials. They are based on homogenization of fibrous networks and calculation of their mostly anisotropic properties that depend strongly on orientation distribution of fibres. More information regarding these models can be found elsewhere [34,35,36]. An amniotic fibrous microstructure was presented by a sparse network in [37], in which fibre interconnections (crosslinks) were randomly distributed ensuring no free fibres and crosslinks. Microstructural features of planar fibrous tissues and scaffolds such as fibre orientation, density and connectivity, fibre intersection densities were detected in SEM images and quantified with a software algorithm $[38,39]$. Fibre density and orientation distribution functions obtained with the same software were recalled to reproduce a microstructure of planar layered elastomeric biomaterials with similar fibre orientation and distribution [40].

Generally, numerical approaches, e.g. discontinuous finite element (FE) modelling, replicating mechanical behaviour of fibrous networks, could provide a feasible way to overcome limitations of experimental studies. A discontinuous FE model can introduce directly microstructure of the material incorporating such specific features as randomly oriented fibres, pores, and fibre intersections. This provides a better understanding of actual processes in the material's microstructure under variety of loading conditions. Such a discontinuous (microstructural) FE model allows both understanding of mechanical responses and optimization and it needs properties of constituent's microstructural morphology, etc. Therefore, capability of the model depends on quality of material properties and reflection of geometries of a real material. For fibrous hydrogels, the main challenge would be to obtain stiffness of their nanofibres.

In this study, inspired by inverse parameter estimation, a numericalexperimental framework is suggested, combining in-aqua mechanical testing, microstructural analysis and discontinuous finite-element modelling, to determine stiffness of $\mathrm{BC}$ nanofibres. The obtained results are assessed by calibrating results of the FE model with our experimental data. This approach shows a high potential for characterisation of nanofibres in hydrogels.

\section{Framework for inverse parameter estimation}

The main idea of inverse parameter estimation for determination of the axial modulus of nanofibres in hydrogels is to (i) develop a realistic microstructural FE model based on micro-morphological observations; (ii) approximate a value of the axial modulus of fibres; (iii) calibrate the approximated value with experimental data. Main elements of the combined approach used in this study are illustrated in Fig. 1, while their brief description is given here.

\subsection{Mechanical testing}

Dog-bone specimens of hydrogels were firstly stretched to various strain levels, then held for $300 \mathrm{~s}$ and, finally, unloaded by $1 \%$ strain with reference to the deformed specimens. The output of these tests was deformed specimens and the initial unloading modulus, which represents an effective modulus of the whole specimen at a certain strain level.

\subsection{Structural feature analysis}

The deformed specimens were used to assess their microstructural features for development of model geometries. The volume fraction was used to calculate an average distance between fibrous layers; combining it with the effective modulus of specimens, the effective modulus of a sub-layer was then determined for validation of modelling results.

\subsection{Finite-element modelling}

Based on real microstructural features obtained from SEM images, an initial 2D model with random distribution of fibres was developed. In order to optimize the model, three numerical studies - model-size convergence, mesh sensitivity and volume-averaging (effect of randomness) - were carried out; as a result, a representative volume element (RVE) was identified. Then, an orientation distribution of fibres from structural analysis was implemented to develop a microstructural model of a deformed fibrous network.

\subsection{Data analysis}

In a quasi-static tension regime, an elastic response of the RVE with a specific orientation distribution of fibres was obtained together with an approximate value of the axial modulus; then, it was calibrated with experimental data to the estimate axial modulus of $\mathrm{BC}$ nanofibres.

\section{Mechanical testing}

\subsection{Materials and specimen preparation}

BC was biosynthesized by Gluconacetobacter xylinus (ATCC53582). The bacteria were grown on a Hestrin and Schramm (HS) medium containing citric acid $0.15 \%(\mathrm{w} / \mathrm{v})$, disodium phosphate $\left(\mathrm{Na}_{2} \mathrm{HPO}_{4}\right) 0.27 \%$ $(\mathrm{w} / \mathrm{v})$, yeast extract powder $0.5 \%(\mathrm{w} / \mathrm{v})$, peptone $0.5 \%(\mathrm{w} / \mathrm{v})$ and glucose $2 \%(\mathrm{w} / \mathrm{v})$. The HS medium was sterilized for $20 \mathrm{~min}$ at $121^{\circ} \mathrm{C}$. After incubation for 10 days at $30^{\circ} \mathrm{C}$, bacteria and proteins in the $\mathrm{BC}$ films were eliminated by boiling in $1 \mathrm{wt} \% \mathrm{NaOH}$ for $30-45 \mathrm{~min}$. Subsequently, the produced samples of hydrogels were washed with distilled water and high-purity water several times until their $\mathrm{pH}$ reached 7.0. The films were then sterilized for $20 \mathrm{~min}$ at $121^{\circ} \mathrm{C}$ and stored in sterilized water at $4{ }^{\circ} \mathrm{C}$. Films were incubated into DI water at room temperature for $12 \mathrm{~h}$ before cutting the specimen. Dog-bone-shape specimens were cut with a custom-made die with their dimensions suggested by ASTM 638-10 standard (detailed information can be found in [12]).

\subsection{Measurement of effective elastic modulus}

The BC hydrogel is practically a viscoelastic material thanks to its high liquid content $[41,42]$. Motion of water during a process of deformation is involved in the network's response, affecting the measurements of its stiffness [43]. In this study, an initial unloading tangent modulus was used as effective elastic property of bulk specimens 


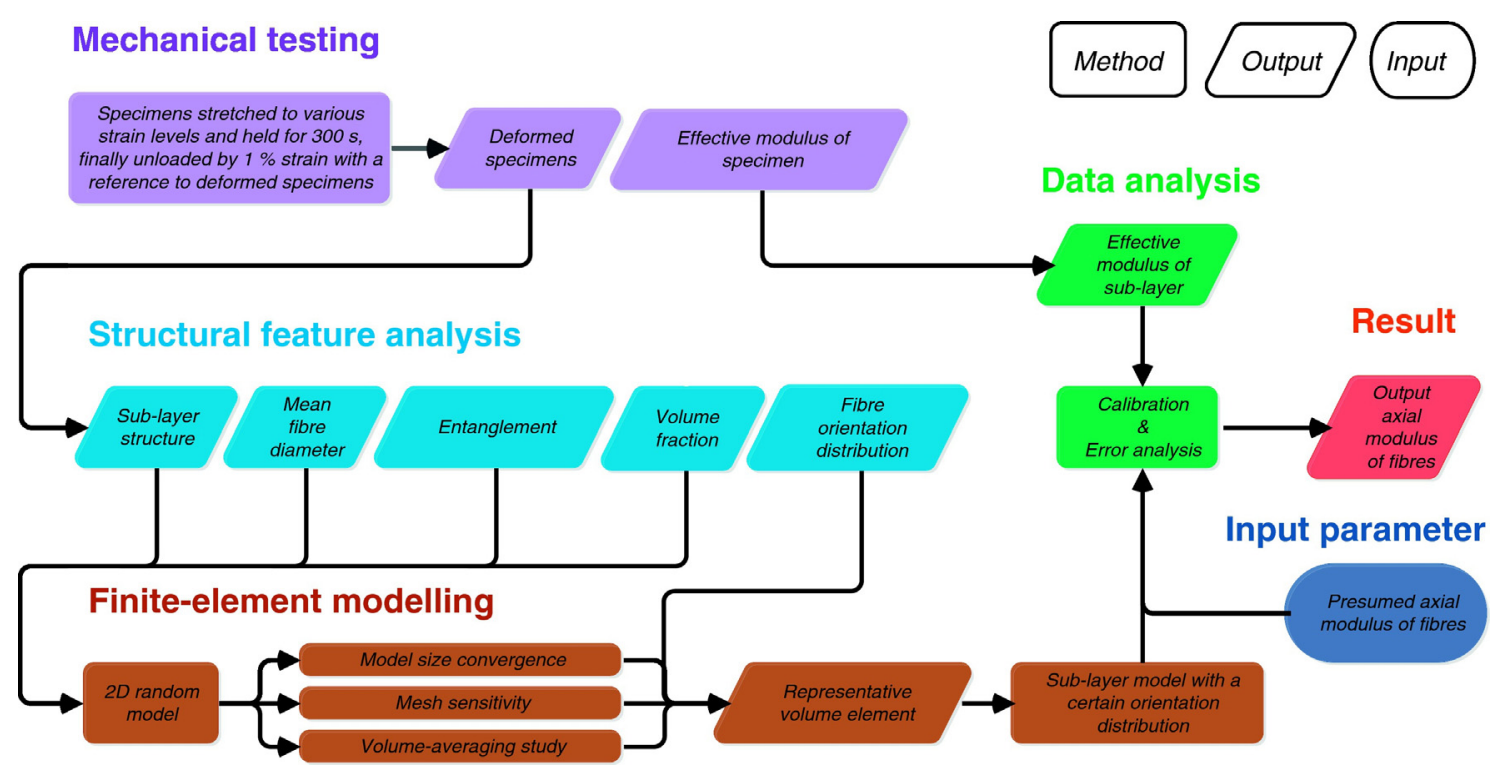

Fig. 1. Flowchart of numerical-experimental framework.

based on inelastic behaviour from our previous research [12]. It is assumed that the initial unloading behaviour is purely elastic due to the limited time. Hence, specimens $(n=5)$ were firstly stretched in aqua to five strain levels ranging from $20 \%$ to $60 \%$ at strain rate of $0.001 \mathrm{~s}^{-1}$, and then the attained level of displacement was hold for
$300 \mathrm{~s}$ to reduce the effect of water motion; finally, specimens were unloaded by $1 \%$ strain at the same strain rate (Fig. 2e). The measured values of effective stiffness $E_{\text {eff }}$ are summarized in Table 1.

A universal testing machine (Instron 3366, Instron, USA) with a biobath system (Instron 3130-100 BioPuls Bath, Instron, USA) was used for
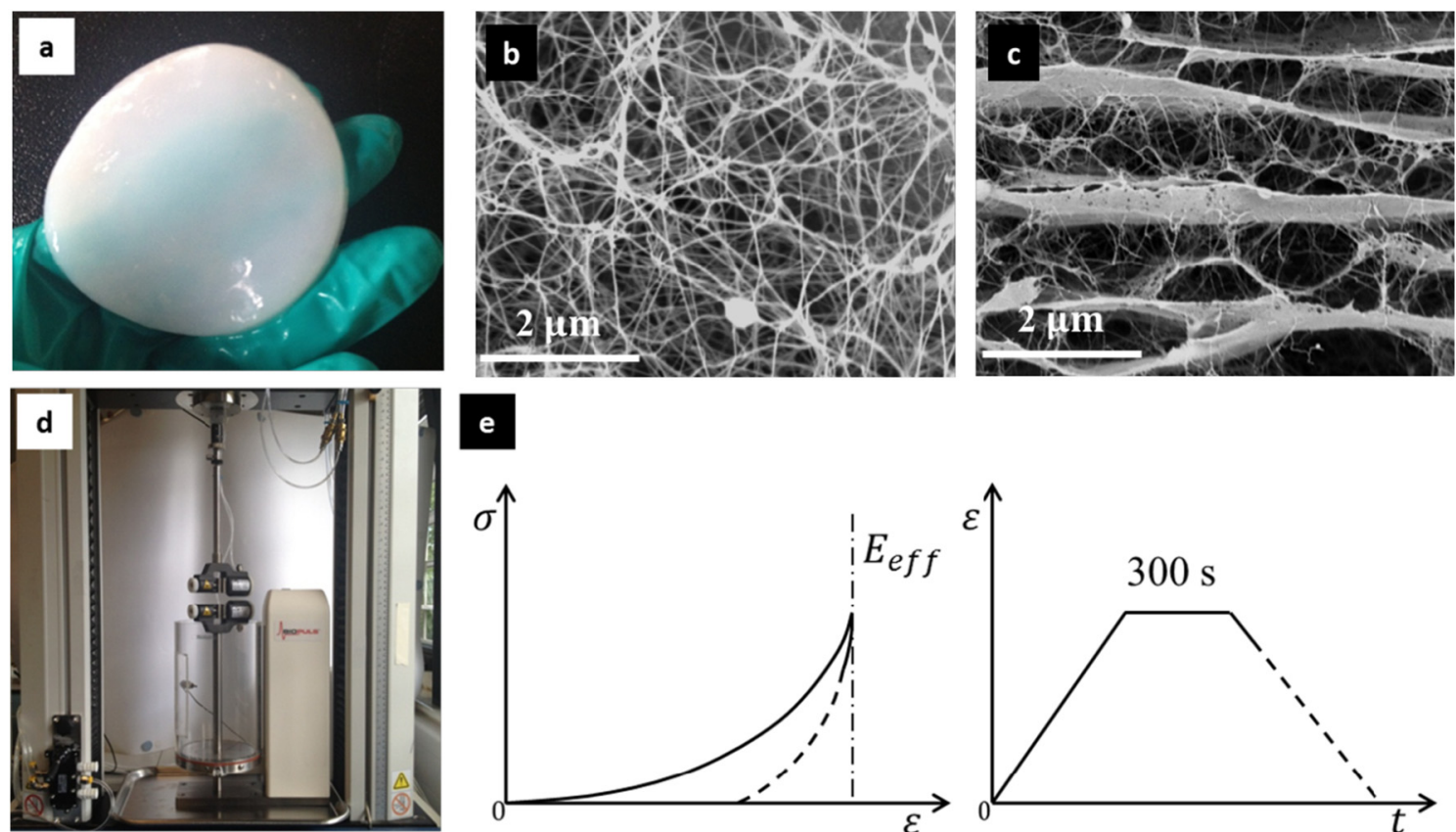

e
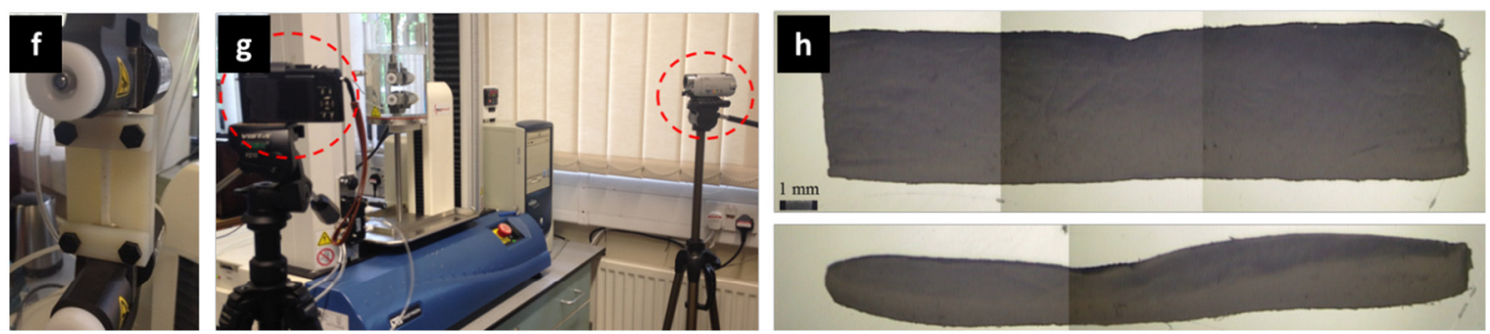

Fig. 2. (a) Bacterial cellulose hydrogel; (b) random distribution of $B C$ nanofibres in fibrous layer; (c) multi-layer structure with some weak cross-links; (d) Instron 3366 used with BioPuls Bath system for uniaxial in aqua tension; (e) schematic diagram for obtaining effective elastic modulus of bulk material; (f) custom-made fixture to clamp stretched specimens to avoid elastic recovery; (g) two digital cameras to assess geometric changes of specimens; (h) optical microscopy images of freeze-dried specimens to calculate total volume. 
Table 1

Characteristic parameters of $\mathrm{BC}$ network after various strain levels of stretching

\begin{tabular}{lllll}
\hline $\begin{array}{l}\text { Strain } \\
\text { level, \% }\end{array}$ & $\begin{array}{l}\text { Variance } \\
\text { parameter } \beta\end{array}$ & $\begin{array}{l}\text { Effective } \\
\text { modulus } E_{\text {eff, }} \\
\mathrm{MPa}\end{array}$ & $\begin{array}{l}\text { Volume } \\
\text { fraction } V_{f}, \%\end{array}$ & $\begin{array}{l}\text { Distance between } \\
\text { fibrous layers } H, \mu m\end{array}$ \\
\hline 20 & 42.7 & $24.37 \pm 4.22$ & $4.96 \pm 0.56$ & 2.70 \\
30 & 33.24 & $43.48 \pm 4.59$ & $6.57 \pm 0.75$ & 2.04 \\
40 & 29.56 & $61.14 \pm 8.32$ & $8.72 \pm 1.12$ & 1.54 \\
50 & 27.98 & $79.61 \pm 5.69$ & $10.85 \pm 0.99$ & 1.24 \\
60 & 23.50 & $90.37 \pm 9.12$ & $11.35 \pm 1.05$ & 1.18 \\
\hline
\end{tabular}

tensile tests (Fig. 2d). Force and displacement data were recorded at $10 \mathrm{~Hz}$ with a $100 \mathrm{~N}$ load cell (2530 Series Low-profile Static Load Cell, Instron, USA) and a displacement sensor of the Instron machine, respectively. In order to obtain statistic data on orientation distribution of nanofibres, corresponding to initial unloading tangent modulus, the stretched specimens were clamped in a custom-made fixture to avoid the recovery of microstructure after removal of the tensile load (Fig. 2f). Two digital cameras were used to record geometric changes of specimens for evaluation of an instantaneous cross-sectional area (Fig. 2g).

\section{Structural feature analysis}

\subsection{Measurement of volume fraction of fibres of stretched specimens}

The water in stretched specimens was removed by freeze-drying for $24 \mathrm{~h}$. Then, a rectangular part was cut from the gauge length of the stretched specimen. The geometries of these parts were captured with optical microscopy to calculate their total volume (Fig. 2h). Then, the parts were weighed with accuracy of $\pm 0.0001 \mathrm{~g}$. The cellulose volume fraction of the whole specimen $V_{f}$ was calculated as

$V_{f}=\frac{m / \rho}{V}$

where $m$ is the dry mass, $\rho$ is the density of cellulose fibre (1592 kg/m ${ }^{3}$ [44]), $V$ is the total volume. The value of $V_{f}$ at each strain level can be found in Table 1 .

\subsection{Statistics of fibre orientation}

The cut sections were gold-coated, and then their morphology was studied with a high-resolution field emission gun scanning electron microscope (FEG-SEM) operated at 5 kV (LEO 1530 VP, ZEISS, Germany). FEG-SEM images were taken at magnifications of $100 \times, 1000 \times$ and $5000 \times$ (Fig. 3). The statistic data of fibre orientation was obtained with image analysis. Then, these data of fibre orientation at each strain level were fit with a normal distribution function, used subsequently to implement fibre distribution in the FE model (Fig. 4). The variance parameter $\beta$ of the normal distribution function for each strain level is given in Table 1. Apparently, in the process of stretching, one of the main microstructural changes induced in the fibrous network is re-orientation of fibres towards the direction of deformation; this process was observed in various networks (see e.g. [45]).
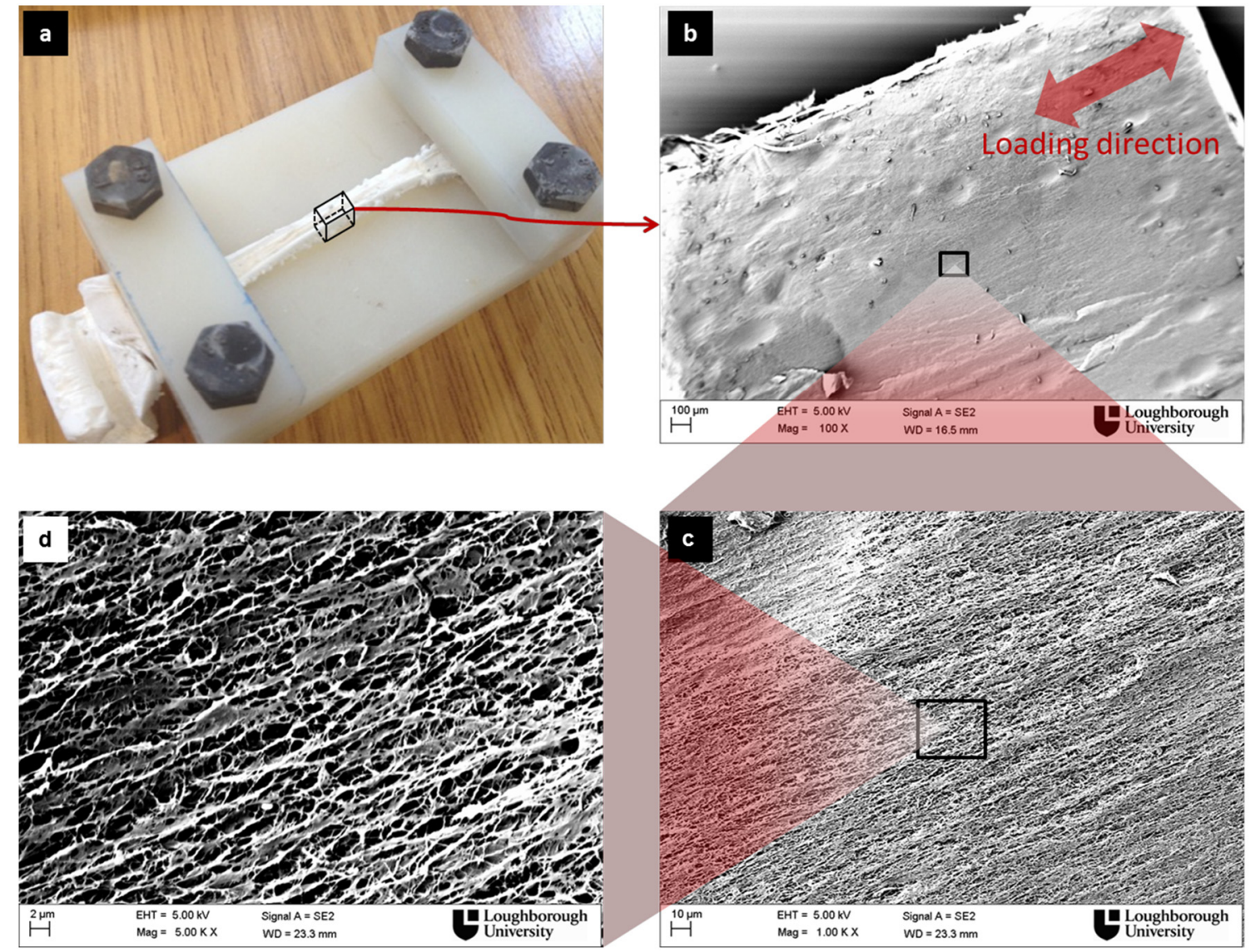

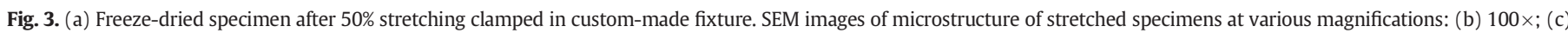
$1000 \times$; (d) $5000 \times$ 

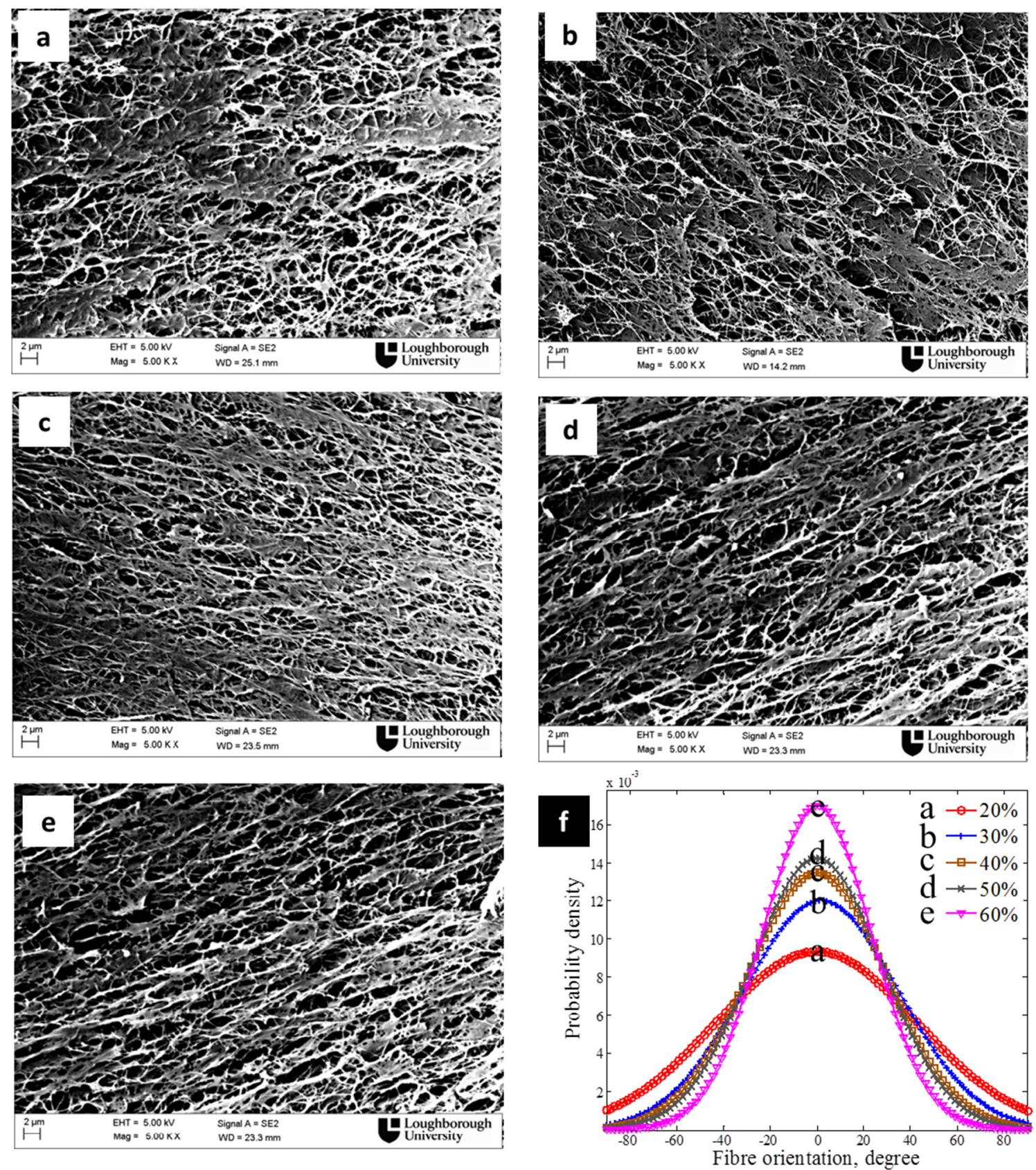

Fig. 4. Orientation distribution of fibres at strain level of $20 \%$ (a), $30 \%$ (b), $40 \%$ (c), $50 \%$ (d) and $60 \%$ (e) and their normal distributions (f) ( $0^{\circ}$ corresponds to the stretching direction).

\subsection{Network structure of BC hydrogel}

A solid phase of BC hydrogel is a multi-layerd scaffold with some cross-link fibres to interconnect fibrous layers [42] (Fig. 2c). Based on the micro-morphology observations, a BC fibrous layer consists of dense fibres (Fig. 5a); while, an image of a single mesh-like network vividly demonstrates that porosity is higher than that of a fibrous layer (Fig. 5b). The levels of porosity measured with image analysis in the fibrous layer and the single mesh-like network were $22.2 \%$ and $65.0 \%$, respectively. In a 2D case, considering the overlapping domains, it was assumed (based on SEM analysis) that an avergaged value of three 2D mesh-like networks (sub-layers) were compacted in 3D to form one fibrous layer. Also, the diameter and aspect ratio of segments of fibres between their intersections were obtained with image analysis with mean values of $\sim 130 \mathrm{~nm}$ (similar magnitudes were obtained in the study of Grande et al. [46]) and 10, respectively. A simplified geometric sketch of represent the BC hydrogel is presented in Fig. 5c.

\section{Finite-element modelling}

\subsection{Generation of FE model}

In a case of uniaxial load applied parallel to fibrous layers, in-plane fibres make the major contribution to load bearing; thus, the effect of cross-links between the layers and interaction between sub-layers (e.g. friction) are negligibly small. Hence, to simplify a computational scheme, a 2D model of a sub-layer is sufficient to represent behaviour of the whole material.

Considering that a calibration process would necessitate over a hundred of statistical realizations of distribution of fibres, a Python ${ }^{\circledR}$ code was developed for pre-processing of a FE model to introduce a random fibrous network with controlled fibre orientations and their volume fraction. In this study, MSC Marc ${ }^{\circledR}$ was used for preprocessing, solving the nonlinear structural equations and post-processing. To simplify the analysis, all the fibre-segments were 

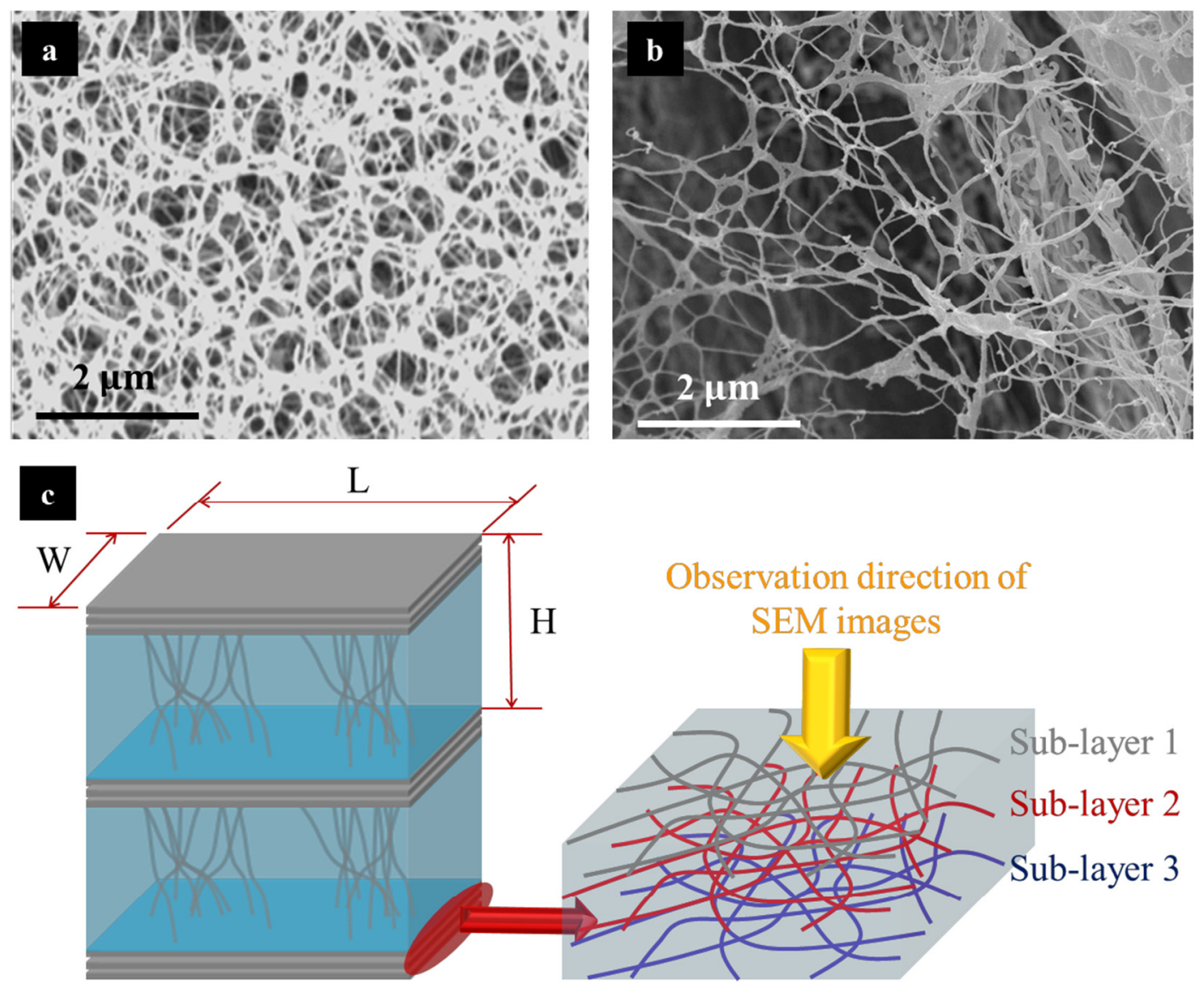

Fig. 5. SEM images of nanofibrous networks in layer $(5000 \times)$ (a) and single sub-layer $(5000 \times)$ (b). It was found that a single fibrous layer consisted of three sub-layers (c).

considered as straight cylinders with a constant diameter of $130 \mathrm{~nm}$. A sample of developed model geometries can be found in Fig. 6; while the detailed model development will be published elsewhere.
The model is constrained at its left-hand side along the loading direction and stretched with a constant strain rate, reproducing conditions of the experiments.

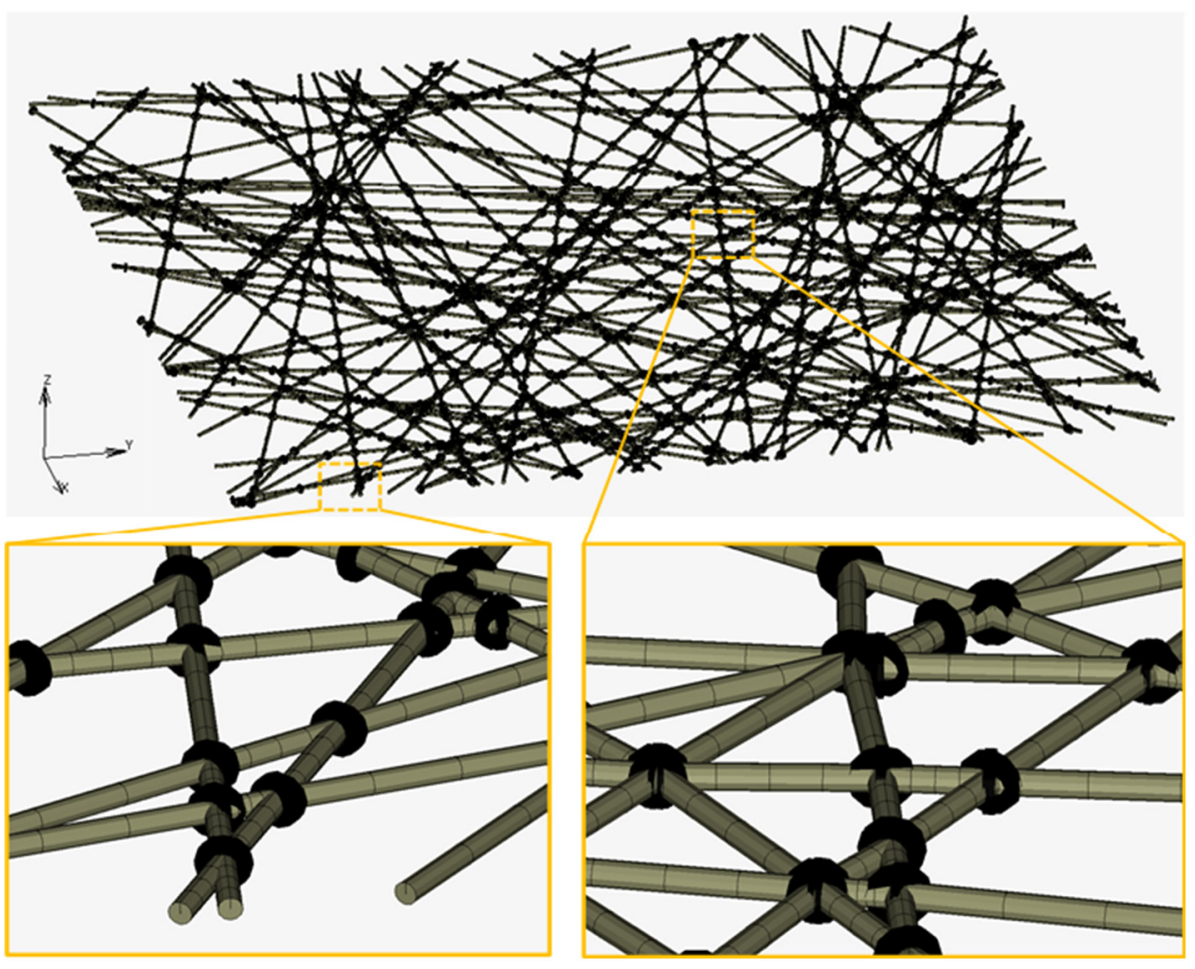

Fig. 6. A random model with detailed information to show model geometries. 


\subsection{Representative volume element}

Considering the size of nanofibres, hundreds of millions of fibre-elements and intersections are required to account for dimensions of the used testing specimens, making the computational cost prohibitive. One of the feasible approaches to solve this problem is to use a representative volume element (RVE) [47]. An effective way to qualify whether a specific model can be treated as RVE is by testing its property of representativeness; in other words, properties of interest should be model-independent. In this study, three studies - model-size convergence, mesh-size sensitivity and volume-averaging properties - were carried out for that goal.
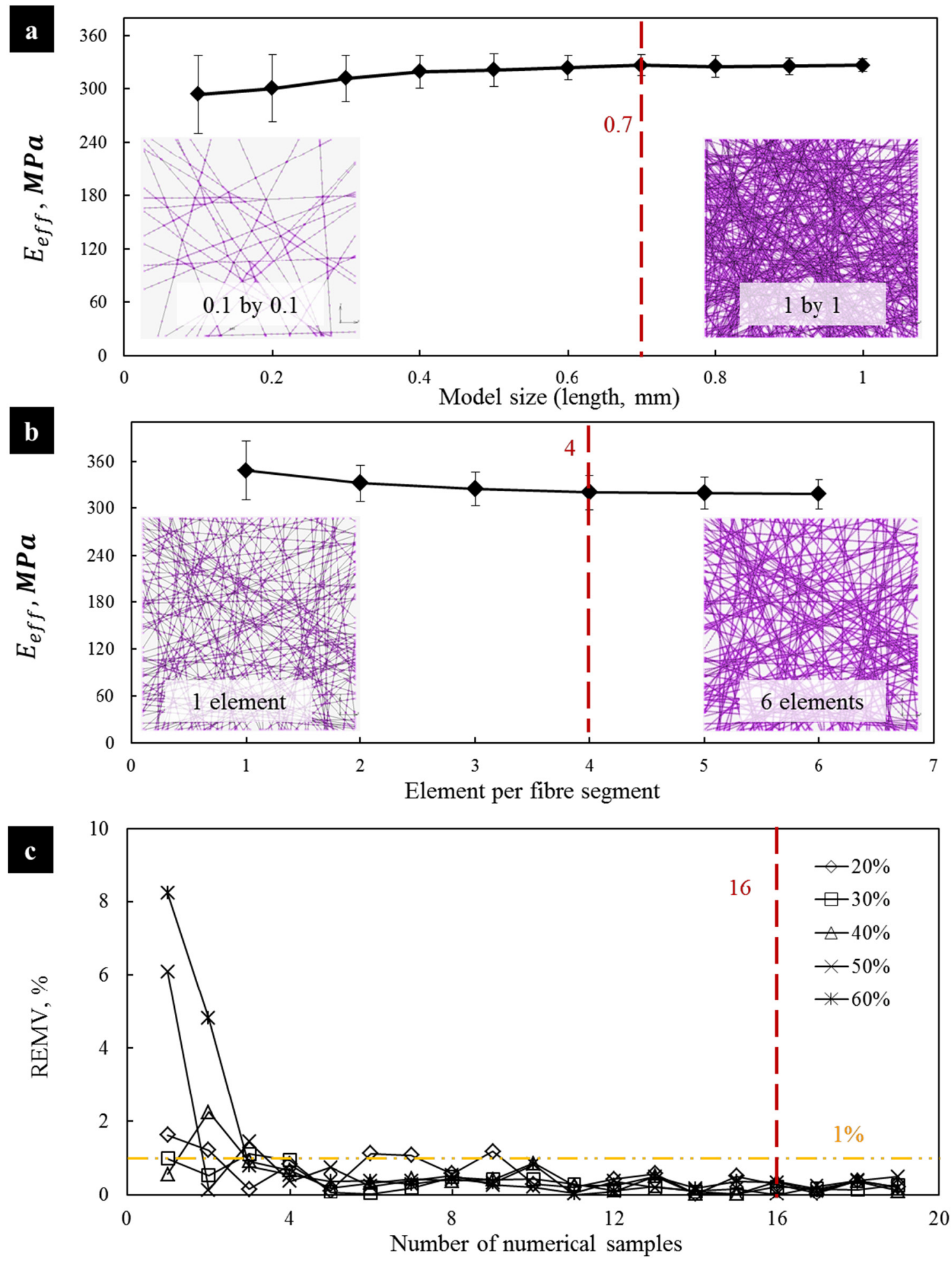

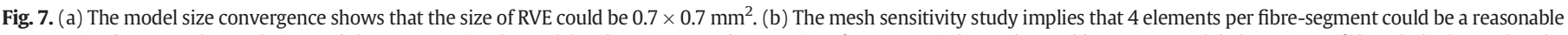

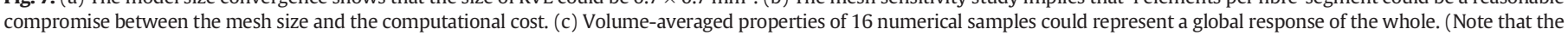
input value of stiffness of $50 \mathrm{GPa}$ was used in these studies.) 
- Numerical samples of statistical realizations $(n=30)$ with random fibre orientation and various model sizes increasing from $0.1 \times$ $0.1 \mathrm{~mm}^{2}$ to $1 \times 1 \mathrm{~mm}^{2}$ were developed, and then applied with the same quasi-static loading conditions (Fig. 7a).

- Thirty numerical samples $\left(0.7 \times 0.7 \mathrm{~mm}^{2}\right)$ with various mesh sizes from 1 to 6 elements per fibre segment - were used in the mesh-sensitivity study (Fig. 7b).

- Numerical samples $\left(n=30,0.7 \times 0.7 \mathrm{~mm}^{2}, 4\right.$ elements per fibre segment) with fibre orientation distribution corresponding to strains from $20 \%$ to $60 \%$ were developed for the volume-averaging study (Fig. 7c). It was stated $[48,49]$ that the averaged properties tended to converge when the amount of numerical samples is large enough, assessed by a tendency of a relative error of mean value (REMV) according to the following expressions:

$\mathrm{REMV}=\frac{\left|M_{n+1}-M_{n}\right|}{M_{n+1}} \times 100 \%, M_{n}=\frac{\sum_{i=1}^{n} Q_{i}}{n}$,

where $Q_{i}$ is the value of sample $i, M_{n}$ is the mean value for $n$ samples.

The results of these three studies suggest that the model with size of $0.7 \times 0.7 \mathrm{~mm}^{2}, 4$ mesh elements per fibre segment can be treated as RVE in this study. Properties averaged for 16 numerical samples could represent global response of the whole material reasonably well.

\section{Results and discussion}

The obtained level of porosity of a single sub-layer (65.0\%) was calculated by image analysis so that the cellulose content (35.0\%) represents an area ratio in a $2 \mathrm{D}$ case. In order to convert the area ratio into a volume fraction, it was assumed that a single sub-layer has constant thickness equal to the diameter of fibres $(130 \mathrm{~nm})$; then, the volume fraction of a single sub-layer $v_{f}$ was estimated as

$v_{f}=\frac{\pi}{4} A_{f}$,

where $A_{f}$ is the area ratio. Based on the micro-morphological observations, one fibrous layer is composed of three parallel sub-layers (Fig. $5 \mathrm{c}$ ), with some $20 \%$ of fibres acting as cross-links between the fibrous layers. Thus, an average distance between fibrous layers $H$ (Fig. 5c) could be calculated as

$H=\frac{3 D v_{f}}{0.8 V_{f}}$,

where $D$ is the average fibre diameter, representing the thickness level of the sub-layer. The values of $H$ for each strain level are summarized in Table 1. Apparently, axial stretching of hydrogel specimens resulted in their lateral (through-thickness) thinning, i.e. decrease of $H$. The studied $B C$ hydrogel could be treated as an assembly of periodic layers (three sub-layers plus one liquid layer) with thickness $H$ arranged in parallel. Thereby, the effective modulus of one sub-layer $E_{\text {net }}^{E x p}$, obtained from experimental tests and assessments of microstructure, can be calculated as

$E_{\text {net }}^{\text {Exp }}=\frac{H E_{\text {eff }}}{D}$.

Obviously, this value should be used as a reference for the magnitudes of network's stiffness obtained in the numerical simulations; this is illustrated in Fig. 8a. Since the level of stiffness of nanofibres is not known a priori - rather, it is a sought parameter, various value of the approximate axial modulus $\overline{E_{f}}$ were implemented in RVE - based simulations. The effective modulus of model $E_{\text {net }}^{\text {Mod }}$ obtained for various values of $\overline{E_{f}}$ at each strain level were determined (they are shown as red-dash lines in Fig. 8a). The axial modulus at each strain level was calibrated with the modelling results, and the respective values can be found in Fig. 8a. It demonstrates that the axial modulus of BC nanofibres falls within a range approximately between 50 and 65 GPa. Especially, the fit results for strains of $30 \%, 40 \%, 50 \%$ and $60 \%$ are close to each other. It should be noted that the microstructure would be modified by stretching induced to various strain levels, resulting in different effective moduli, volume fractions, etc.; while, the axial modulus (stiffness) of fibres would substantially remain the same. Hence, to have a unique value matching cases of all strain levels is essential. An error evaluation of relative mean deviation (RMD) was applied to obtain the most suitable magnitude of fibre stiffness:

$\mathrm{RMD}=\frac{1}{n} \sum \frac{\left|E_{\text {net }}^{\text {Mod }}\right|_{\varepsilon}-\left.E_{\text {net }}^{E x p}\right|_{\varepsilon} \mid}{\left.E_{\text {net }}^{\text {Exp }}\right|_{\varepsilon}}$,

where $\left.E_{\text {net }}^{\text {Mod }}\right|_{\varepsilon}$ and $\left.E_{\text {net }}^{\text {Exp }}\right|_{\varepsilon}$ are the effective modulus at the strain level $\varepsilon$ calculated from modelling and experiments, respectively. As shown in Fig. 8 b, an error margin of $10 \%$ was considered in this study, and the axial modulus of $\mathrm{BC}$ nanofibres was calibrated within a range between 53.7 and $64.9 \mathrm{GPa}$ with a minimal mean deviation of $3.6 \%$ at $60.6 \mathrm{GPa}$.

The level of stiffness calculated in this work is somewhat smaller than the values documented in other direct measurements based on testing with AFM and Raman spectroscopy. It has a natural explanation: this study used fully hydrated BC hydrogel, and to the best of our knowledge, the studied material in direct measurement was not fully hydrated. Thus, the potential reason might be that the bound water surrounding the fibres resulted in their softening.
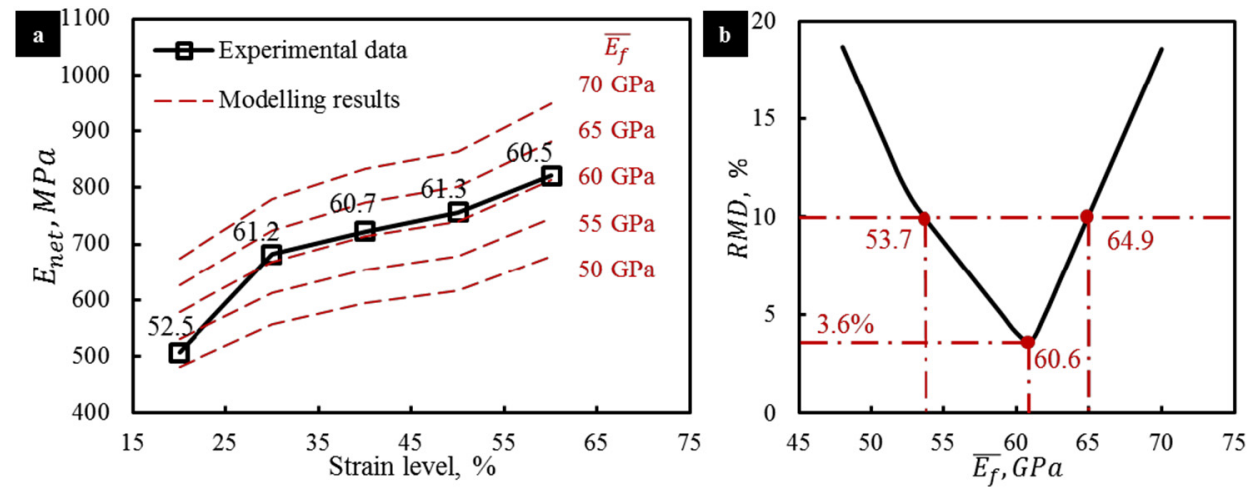

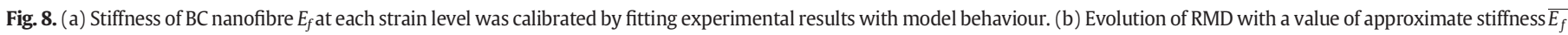
suggests a range of $E_{f}$ for a $10 \%$ error. 


\section{Conclusion}

A growing interest in fibrous hydrogels related to their promise as potential candidates for biomedical applications presupposes a comprehensive understanding of their mechanical response that can be used for design and optimisation of various artificial components. As a major input into FE models, stiffness of nanofibres is a major parameter. So, a numerical-experimental framework was developed and implemented to assess stiffness of the BC nanofibres. The initial unloading behaviour of specimens after a certain level of stretching in tensile in-aqua tests can be assumed as purely elastic making a basis for stiffness assessment. Morphological observations allowed us to identify structural features of the nanofibrous network for both calculating effective stiffness of layered structure from the experimental data and developing geometries of discontinuous FE models. RVEs with actual geometries were developed and used in simulations with a range of approximate values of stiffness of $\mathrm{BC}$ nanofibres in order to match the experimental data. The obtained levels of stiffness between 53 and $65 \mathrm{GPa}$ (for 10\% error) and the best value of $60.6 \mathrm{GPa}$ - are comparable with results obtained with nano-testing, suggesting a potential to use this framework to determine stiffness of nanofibres in hydrogels, and other networks.

\section{Acknowledgement}

The authors would like to acknowledge the 7th European Community Framework Programme for financial support through a Marie Curie International Research Staff Exchange Scheme (IRSES) Project entitled "Micro-Multi-Material Manufacture to Enable Multifunctional Miniaturised Devices (M6)" (Grant No. PIRSES-GA-2010-269113). Additional support from China-European Union Technology Cooperation Programme (Grant No. 1110) is also acknowledged.

\section{References}

[1] L. Nimeskern, H.M. Avila, J. Sundberg, P. Gatenholm, R. Muller, K.S. Stok, Mechanical evaluation of bacterial nanocellulose as an implant material for ear cartilage replacement, J. Mech. Behav. Biomed. Mater. 22 (2013) 12-21.

[2] J. Wang, C. Gao, Y. Zhang, Y. Wan, Preparation and in vitro characterization of BC/ PVA hydrogel composite for its potential use as artificial cornea biomaterial, Mater. Sci. Eng. C 30 (2010) 214-218.

[3] J. Malho, P. Laaksonen, A. Walther, O. Ikkala, M.B. Linder, Facile method for stiff, tough, and strong nanocomposites by direct exfoliation of multilayered graphene into native nanocellulose matrix, Biomacromolecules 13 (2012) 1093-1099.

[4] S. Zang, R. Zhang, H. Chen, Y. Lu, J. Zhou, X. Chang, G. Liu, Z. Wu, G. Yang, Investigation on artificial blood vessels prepared from bacterial cellulose, Mater. Sci. Eng. C 46 (2015) 111-117.

[5] F.K. Andrade, R. Costa, L. Domingues, R. Soares, M. Gama, Improving bacterial cellulose for blood vessel replacement: functionalization with a chimeric protein containing a cellulose-binding module and an adhesion peptide, Acta Biomater. 6 (2010) 4034-4041.

[6] M. Zaborowska, A. Bodin, H. Bäckdahl, J. Popp, A. Goldstein, P. Gatenholm, Microporous bacterial cellulose as a potential scaffold for bone regeneration, Acta Biomater 6 (2010) 2540-2547.

[7] H. Bäckdahl, G. Helenius, A. Bodin, U. Nannmark, B.R. Johansson, B. Risberg, P. Gatenholm, Mechanical properties of bacterial cellulose and interactions with smooth muscle cells, Biomaterials 27 (9) (2006) 2141-2149.

[8] H. Bäckdahl, M. Esguerra, D. Delbro, B. Risberg, P. Gatenholm, Engineering microporosity in bacterial cellulose scaffolds, J. Tissue Eng. Regen. Med. 2 (6) (2008) 320-330.

[9] G. Helenius, H. Backdahl, A. Bodin, U. Nannmark, P. Gatenholm, B. Risberg, In vivo biocompatibility of bacterial cellulose, J. Biomed. Mater. Res. A 76A (2006) 431-438.

[10] Z. Shi, Y. Zhang, G.O. Phillips, G. Yang, Utilization of bacterial cellulose in food, Food Hydrocoll. 35 (2014) 539-545.

[11] C.T. Koh, D.G.T. Strange, K. Tonsomboon, M.L. Oyen, Failure mechanisms in fibrous scaffolds, Acta Biomater. 9 (2013) 7326-7334.

12] X. Gao, Z. Shi, C. Liu, G. Yang, I. Sevostianov, V.V. Silberschmidt, Inelastic behaviour of bacterial cellulose hydrogel: in aqua cyclic tests, Polym. Test. 44 (2015) 82-92.

[13] W. Zhao, C. Liu, F. Wu, C. Lenardi, Investigation on the mechanical behaviour of poly(hydroxyethyl methacrylate) hydrogel membrane under compression in the assembly process of microfluidic system, J. Polym. Sci. B 52 (2014) 485-495.

[14] W. Zhao, Z. Shi, X. Chen, G. Yang, C. Lenardi, C. Liu, Microstructural and mechanical characteristics of PHEMA-based nanofibre-reinforced hydrogel under compression, Compos. Part B Eng. 76 (2015) 292-299.
[15] T. Courtney, M.S. Sacks, J. Stankus, J. Guan, W.R. Wagner, Design and analysis of tissue engineering scaffolds that mimic soft tissue mechanical anisotropy, Biomaterials 27 (2006) 3631-3638.

[16] N.J. Amoroso, A. D'Amore, Y. Hong, W.R. Wagner, M.S. Sacks, Elastomeric electrospun polyurethane scaffolds: the interrelationship between fabrication conditions, fiber topology, and mechanical properties, Adv. Mater. 23 (2011) $106-111$.

[17] E.P.S. Tan, C.T. Lim, Mechanical characterization of nanofibers - a review, Compos. Sci. Technol. 66 (2006) 1102-1111.

[18] E.P.S. Tan, C.N. Goh, C.H. Sow, C.T. Lim, Tensile test of a single nanofiber using an atomic force microscope tip, Appl. Phys. Lett. 86 (2005) 073115

[19] Q. Cheng, S. Wang, A method for testing the elastic modulus of single cellulose fibrils via atomic force microscopy, Compos. A: Appl. Sci. Manuf. 12 (2008) 1838-1843.

[20] S. Iwamoto, W. Kai, A. Isogai, T. Iwata, Elastic modulus of single cellulose microfibrils from tunicate measured by atomic force microscopy, Biomacromolecules 10 (2009) 2571-2576.

[21] E.P.S. Tan, C.T. Lim, Nanoindentation study of nanofibers, Appl. Phys. Lett. 87 (2005) 123106.

[22] X. Chen, S. Xu, N. Yao, W. Xu, Y. Shi, Potential measurement from a single lead zirconate titanate nanofiber using a nanomanipulator, Appl. Phys. Lett. 94 (2009) 253113.

[23] M. Naraghi, I. Chasiotis, H. Kahn, Y. Wen, Y. Dzenis, Novel method for mechanical characterization of polymeric nanofibers, Rev. Sci. Instrum. 78 (2007) 085108.

[24] G. Guhados, W. Wan, J.L. Hutter, Measurement of the elastic modulus of single bacterial cellulose fibers using atomic force microscopy, Langmuir 21 (2005) 6642-6646.

[25] Y.C. Hsieh, H. Yano, M. Nogi, S.J. Eichhorn, An estimation of the Young's modulus of bacterial cellulose filaments, Cellulose 15 (4) (2008) 507-513.

[26] S. Tanpichai, F. Quero, M. Nogi, H. Yano, R.J. Young, T. Lindström, W.W. Sampson, S.J. Eichhorn, Effective Young's modulus of bacterial and microfibrillated cellulose fibrils in fibrous networks, Biomacromolecules 13 (2012) 1340-1349.

[27] A. Retegi, N. Gabilondo, C. Pena, R. Zuluaga, C. Castro, P. Ganan, K. de la Caba, Bacterial cellulose films with controlled microstructure-mechanical properties relationships, Cellulose 17 (2010) 661-669.

[28] G. Josefsson, B.S. Tanem, Y. Li, P.E. Vullum, E.K. Gamstedt, Prediction of elastic properties of nanofibrillated cellulose from micromechanical modeling and nano-structure characterization by transmission electron microscopy, Cellulose 20 (2013) 761-770.

[29] W.A. Bosbach, The elastic behaviour of sintered metallic fibre networks: a finite element study by Beam theory, PLoS ONE 10 (2015) 11.

[30] X. Hou, M. Acar, V.V. Silberschmidt, 2D finite element analysis of thermally bonded nonwoven materials: continuous and discontinuous models, Comput. Mater. Sci. 46 (2009) 700-707.

[31] B. Sabuncuoglu, M. Acar, V.V. Silberschmidt, A parametric finite element analysis method for low-density thermally bonded nonwovens, Comput. Mater. Sci. 52 (2012) 164-170.

[32] F. Farukh, E. Demirci, B. Sabuncuoglu, M. Acar, B. Pourdeyhimi, V.V. Silberschmidt, Numerical modelling of damage initiation in low-density thermally bonded nonwovens, Comput. Mater. Sci. 64 (2012) 112-115.

[33] E. Demirci, M. Acar, B. Pourdeyhimi, VV. Silberschmidt, Computation of mechanical anisotropy in thermally bonded bicomponent fibre nonwovens, Comput. Mater. Sci. 52 (2012) 157-163.

[34] E. Demirci, M. Acar, B. Pourdeyhimi, V.V. Silberschmidt, Dynamic response of thermally bonded bicomponent fibre nonwovens, Appl. Mech. Mater. 70 (2011) 405-409.

[35] A. Ridruejo, C. González, J. LLorca, A constitutive model for the in-plane mechanical behavior of nonwoven fabrics, Int. J. Solids Struct. 49 (2012) 2215-2229.

[36] A. Raina, C. Linder, A homogenization approach for nonwoven materials based on fiber undulations and reorientation, J. Mech. Phys. Solids 65 (2014) 12-34.

[37] A. Mauri, R. Hopf, A.E. Ehret, C.R. Picu, E. Mazza, A discrete network model to represent the deformation behavior of human amnion, J. Mech. Behav. Biomed. Mater. (2015) http://dx.doi.org/10.1016/j.jmbbm.2015.11.009.

[38] A. D'Amore, N. Amoroso, R. Gottardi, C. Hobson, C. Carruthers, S. Watkins, W.R. Wagner, M.S. Sacks, From single fiber tomacro-level mechanics: a structural finite-element model for elastomeric fibrous biomaterials, J. Mech. Behav. Biomed. Mater. 39 (2014) 146-161.

[39] A. D'Amore, J.A. Stella, W.R. Wagner, M.S. Sacks, Characterization of the complete fiber network topology of planar fibrous tissues and scaffolds, Biomaterials 31 (2010) 5345-5354.

[40] J.B. Carleton, A. D'Amore, K.R. Feaver, G.J. Rodin, M.S. Sacks, Geometric characterization and simulation of planar layered elastomeric fibrous biomaterials, Acta Biomater. 12 (2015) 93-101.

[41] X. Gao, Z. Shi, P. Kuśmierczyk, C. Liu, G. Yang, I. Sevostianov, V.V. Silberschmidt, Time-dependent rheological behaviour of bacterial cellulose hydrogel, Mater. Sci. Eng. C 58 (2016) 153-159.

[42] X. Gao, P. Kusmierczyk, Z. Shi, C. Liu, G. Yang, I. Sevostianov, V.V. Silberschmidt, Through-thickness stress relaxation in bacterial cellulose hydrogel, J. Mech. Behav. Biomed. Mater. 59 (2016) 90-98.

[43] X. Gao, Z. Shi, A. Lau, C. Liu, G. Yang, V.V. Silberschmidt, Effect of microstructure on anomalous strain-rate-dependent behaviour of bacterial cellulose hydrogel, Mater. Sci. Eng. C 62 (2016) 130-136.

[44] L.Y Mwaikambo, M.P. Ansell, The determination of porosity and cellulose content of plant fibers by density methods, J. Mater. Sci. Lett. 20 (2001) 2095-2096.

[45] F. Farukh, E. Demirci, B. Sabuncuoglu, M. Acar, B. Pourdeyhimi, V.V. Silberschmidt, Numerical analysis of progressive damage in nonwoven fibrous networks under tension, Int. J. Solids Struct. 51 (2014) 1670-1685. 
[46] C.J. Grande, F.G. Torres, C.M. Gomez, M.C. Bano, Nanocomposites of bacterial cellulose/hydroxyapatite for biomedical applications, Acta Biomater. 5 (2009) 1605-1615.

[47] Q. Liu, Z. Lu, M. Zhu, Z. Yang, Z. Hu, J. Li, Experimental and FEM analysis of the compressive behavior of 3D random fibrous materials with bonded networks, J. Mater. Sci. 49 (2014) 1386-1398.
[48] Q. Liu, Z. Lu, Z. Hu, J. Li, Finite element analysis on tensile behaviour of 3D random fibrous materials: model description and meso-level approach, Mater. Sci. Eng. A 587 (2013) 36-45.

[49] Z. Lu, Q. Liu, H. Han, D. Zhang, Experiment and modeling on the compressive behav-iors for porous silicon nitride ceramics, Mater. Sci. Eng. A 559 (2013) 201209. 